\title{
Transport Properties of Topopah Spring Tuff
}

.

\author{
W. Lin
}

W. Daily

\author{
Manuscript date: October 1984
}

\section{DISCLAMISR}

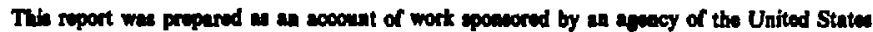

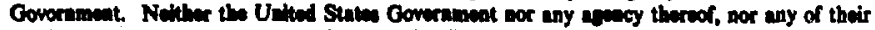

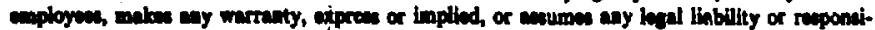

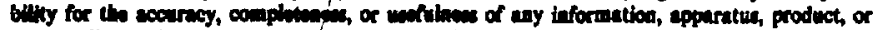

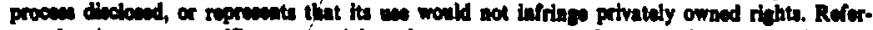

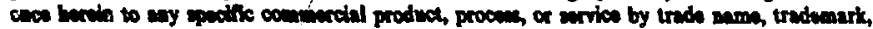

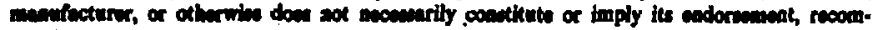

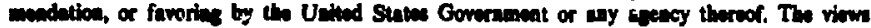

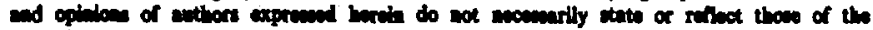

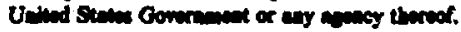

\section{LAWRENCE LIVERMORE NATIONAL LABORATORY University of California - Livermore, California $\cdot 94550$}

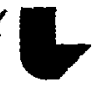




\section{Contents}

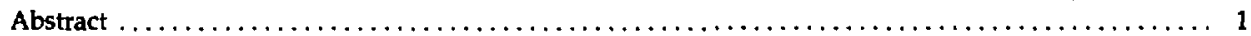

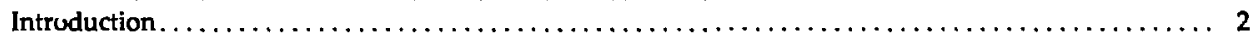

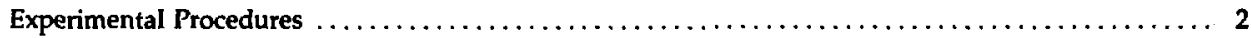

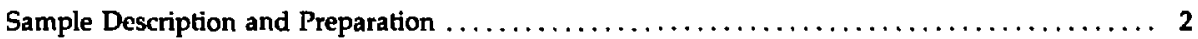

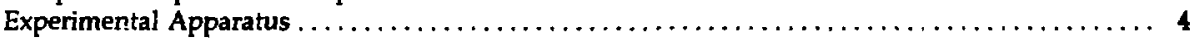

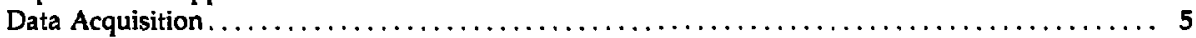

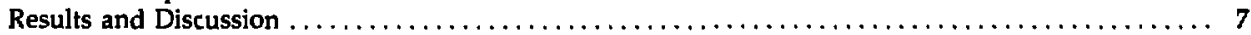

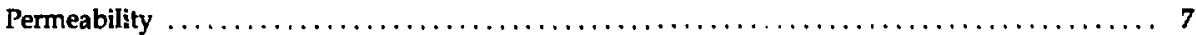

Dehydration Process $\ldots \ldots \ldots \ldots \ldots \ldots \ldots \ldots \ldots \ldots \ldots \ldots \ldots \ldots \ldots \ldots \ldots \ldots \ldots \ldots$

Rehydration Process $\ldots \ldots \ldots \ldots \ldots \ldots \ldots \ldots \ldots \ldots \ldots \ldots \ldots \ldots \ldots \ldots \ldots \ldots \ldots \ldots$

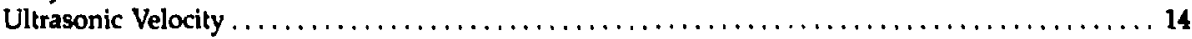

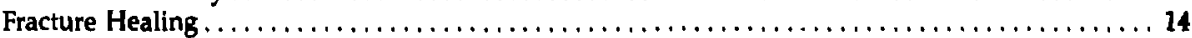

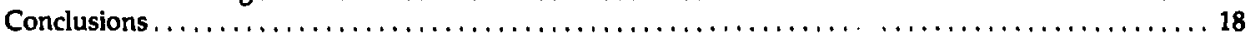

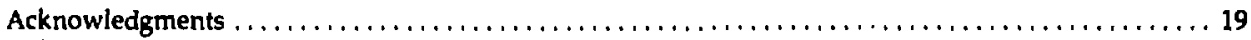

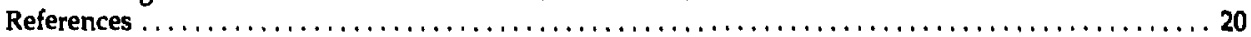




\title{
Transport Properties of Topopah Spring Tuff
}

\begin{abstract}
Electrical resistivity, ultrasoric P-wave velocity, and water permeability were measured simultaneously on both intact and fractured Topopah Spring tuff samples at a confining pressure of $5.0 \mathrm{MPa}$, pore pressures to $2.5 \mathrm{MPa}$, and temperatures to $140^{\circ} \mathrm{C}$. The tested samples were subjected to three dehydration and rehydration cycles. The deliydrations were accomplished at a temperature of $140^{\circ} \mathrm{C}$, and the rehydrations were accomplished at various combinations of temperature and pore pressures so that the wetting fluid was either liquid water, steam, or both.

The electrical resistivity measurements indicate that for the intact sample, the drying and resaturation took place fairly uniformly throughout the sample. On the other hand, for the fractured sample, the drying and resaturation were spatially quite nonuniform. During the drying period, one corner at the upstream end of the fractured sample dried first. When the fractured sample was resaturated, one side of the fracture was wetted first. The nonuniformity in drying and resacuration may be due to the fracture roughness. In addition, when water at a few megapascals of pressure was introduced into the dry fractured sample, the wetting front moved at a speed 100 times faster than in the dry intact rock. Fracture flow dominates the water transport. We saw no evidence for matrix capillarity effect. The resistivity measurements also indicated that, at least in some areas of the samples, drying was accomplished in two stages, and that the fracture acted as a conduit for the steam transport out of the rock. When samples had bcen subjected to $5 \mathrm{MPa}$ of confining pressure and $140^{\circ} \mathrm{C}$ for several weeks, a gradual monotonic drift in resistivity was measured (decreasing resistivity when dry; increasing resistivity when wet). This may be the result of either minerological changes or grain boundary movement. In any case, the phenomenon may have important consequences on long term repository performance, and should be studied further.

The permeability of the intact sample was independent of temperature, dehydration and rehydration cycles, and time. The permeability of the fractured sample, initially dominated by the fracture, decreased by about one order of magnitude after each dehydration and rehydration cycle. In the entire testing period of four monihs, the permeability of the fractured sample decreased by more than threc orders of magnitude ( 850 to $0.3 \mu \mathrm{d})$ until it was the same as that of the intact sample. Testing on a second fractured sample indicated that this decrease in pe hility was due to fracture healing presumably caused by dissolution and redeposition or $s$. ia in the fracture aperture. This deposition occurred as the sample temperature increased to $96^{\circ} \mathrm{C}$ without dehydration of the rock. However, the mechanism for this fracture healing needs further investigation. Permeability of the intact sample did not change under similar conditions. Apparently, silica deposition does not take place in the rock matrix to the degree that it affects permeability.
\end{abstract}




\section{Introduction}

The presence or absence of water in a rock mass has a profound efíect on its geomechanical and geochemical properties. Water has long been recognized as one of the weakening agents of rock. Water affects tectonic processes, such as earthquake activity, folding and faulting of rock formations, etc. ${ }^{2}$ In hydrothermal reactions, water is a major controlling factor. Of course, for the exploitation of geothermal energy, water and steam arc the energy transporting media; but water also contributes to one of the major problems-corrosion. In addition, water will certainly play a major role in leaching and transporting radioactive elements in underground radioactive waste repositories.

The Waste Package Task of the Nevada Nuclear Waste Storage Investigation (NNWS1) Project at Lawrence Livermore National Laboratory (LLNL) sponsors the study reported herein of the dehydration and rehydration processes of rock related to the environment in a nuclear waste repository. In this study, we used measurements of electrical resistivity and ultrasonic wave velocity to monitor the movement of water in drying and saturation of intact and fractured Topopah Spring tuff samples. We also measured water and steam permeability of this tuff when saturated with either water or steam. The experimental conditions were chosen to simulate a nuclear waste repository environment: $5.0 \mathrm{MPa}$ of hydrostatic confining pressure, $P_{c}$ (to simulate lithostatic pressure of about $230 \mathrm{~m}$ depth), up to $2.5 \mathrm{MPa}$ of pore fluid pressure (pore pressure in a typical crustal conditions).

Previous laboratory investigations have shown that saturating a porous rock with water increases electrical conductivity and ultrasonic wave velocity. It has been shown that water saturation may increase P-wave velocity in granite by $10-20 \%$ over values when it is dry. ${ }^{3}$ Motel investigations suggest that this velocity increase due to saturation depends on the effective porosity of the sample. ${ }^{4,5}$ In other words, $P$-wave velocity may depend on the degree of saturation.

In this study, we use various combinations of eight electrcdes placed on the sample to monitor the distribution and contrast in electrical resistivity within the rock when it is dry or saturated. Our purpose is to monitor the movement of moisture (water or steam) during both the drying and saturating processes and to compare the movement in an intact and a fractured sampie.

\section{Experimental Procedures}

\section{Sample Description and Preparation}

Rock samples studied were from the Topopah Spring Member of the Paintbrush Tuff. The two principal samples were machined from outcrop material collected from Fran Ridge at the Nevada Test Site. The site geology is described in detail by Knauss. ${ }^{6}$ An auxiliary sample was obtained from a depth of $373 \mathrm{~m}$ in borehole USW-G1 in Yucca Mountain at the Nevada Test Site. The petrology and geochemistry of this densely welded tuff is reported in detail by Knauss ${ }^{6}$ and Bish.?

Samples were machined to be right circular cylinders about $9.0 \mathrm{~cm}$ long and $2.54 \mathrm{~cm}$ in diameter, with axes approximately perpendicular to the bedding. The edges of each sample were beveled about $2 \mathrm{~mm}$ deep on both ends. The fractured samples were machined from a large core so that a naturally occurring fracture approximately bisected the cylindrical sample longitudinally.
The samples were then dried in a vacuum oven at $30^{\circ} \mathrm{C}$ until their weight remained unchanged for at least one day. Usually, this procedure took more than one week to complete. The samples were then placed in I-13 water at about $0.7 \mathrm{MPa}$ of pressure and reweighed until, again, their weight remained constant for at least one day.

The dry bulk and saturated densities of the samples were calculated from their weights and volumes. The effective porosity was then calculated from the dry and saturated densities. Table 1 lists the dry bulk density and effective porosity of each sample.

Samples were prepared identically wherever possible. Platinum electrodes $0.08 \mathrm{~mm}$ thick, each about $6 \mathrm{~mm}$ square, were used for the electrical resistance measurement. Four pairs of these electrodes were evenly spaced along the axis of each sample. Each pair was placed on a diameter and on opposite sides of the cylindrical surface so that 
current was largely perpendicular to the sample axis. On the first fractured sample, the electrodes were placed as close to the fracture plane as possible. On the second fractured sample, two electrode pairs were placed so that the current was predominantly perpendicular to the fracture surface and two were placed so that current was predominantly parallel (see Fig. 1).

Two ultrasonic piezoelectric transducers (compressional mode) were mounted in the stainless steel end caps (Fig. 1): one served as the P-wave source, and the other as the detector. Also, the pore liquid was introduced into the sample through one end cap and removed through the other. A Viton jacket was used to isolate the sample from the kerosene, the confining pressure medium.

Table 1. Dimersions (diameter $x$ length in $\mathrm{cm}$ ), dry bulk density $(\mathrm{g} / \mathrm{cc})$, and effective porosity of the three Topopah Spring tuff samples.

\begin{tabular}{llll}
\hline & \multicolumn{1}{c}{ Intacl } & \multicolumn{1}{c}{$\begin{array}{c}\text { Fractured } \\
\text { No. 1 }\end{array}$} & $\begin{array}{c}\text { Fractured } \\
\text { No. 2 }\end{array}$ \\
\hline Dimensions & $2.54 \times 10.36$ & $2.54 \times 9.25$ & $2.54 \times 7.62$ \\
Dry bulk density & 2.29 & 2.274 & 2.305 \\
Effective porosity (\%) & 8.1 & 11.3 & 8.4 \\
\hline
\end{tabular}

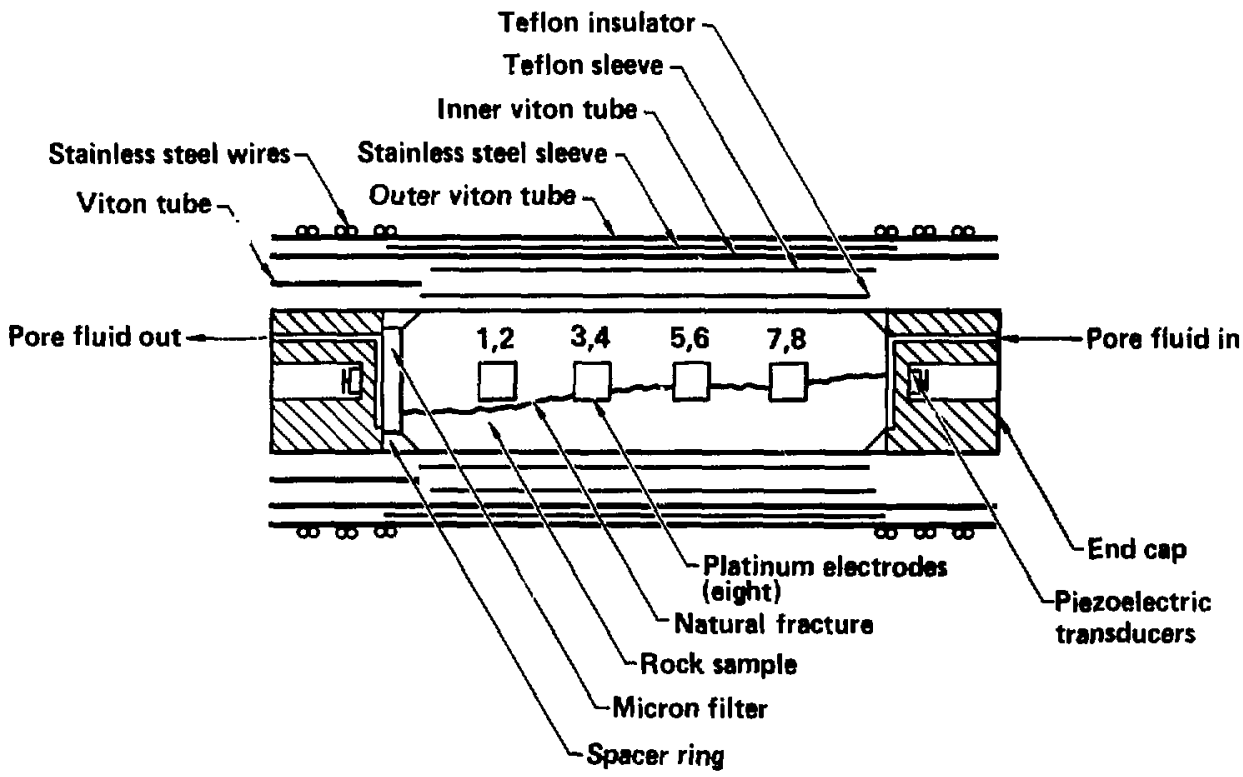

Figure 1. Sample assembly of a fractured sample. The assembly is the same for the intact sample except for the presence of a fracture. 


\section{Experimental Apparatus}

Figure 2 shows the simplified schematic of the experimental apparatus. It consists of three subsystems: the confining pressure system, the pore pressure system to control pore fluid pressure independently, and the electronics and computer system for data acquisition and experimental control.

The confining pressure was generated by a pneumatic pump operating through an intensifier with a 10:1 pressure ratio. The jacketed sample was placed in the pressure vessel, which was heated externally. Both a Heise gage and a pressure transducer were used to measure the confining pressure.

Another pneumatic pump pressurized a large-volume $\mathrm{N}_{2}$-water separator designed to maintain constant pore fluid pressure in the sam. ple. Metering valves located upstream and downstream from the sample allowed control of abso- lute pressure and pressure gradient in the pore fluid of the rock. The steady state flow rate was determined by measuring fluid volume exiting the sample in a given time interval. We used water from well J-13 at the Nevada Test Site as the pore fluid to retain the rock water chemistry that is likely to exist in situ. This water came fuom a well located to the east of Yucca Mountain where the Topopah Spring tuff lies below the water table and is the major producing horizon for the well. The pore fluid pressure gradient was assumed to be linear and was measured by one differential pressure transducer, two absolute pressure transducers, and a Heise gage at the upstream end of the sample (Fig. 2).

The electronics system measured electrical resistarice and P-wave velocity and automatically maintuined the sample at a constant temperature. A commercial automatic conductance bridge measured the resistance between each platinum electrode pair. A Pt-Pt 10\% $\mathrm{Rh}$ thermocouple, located

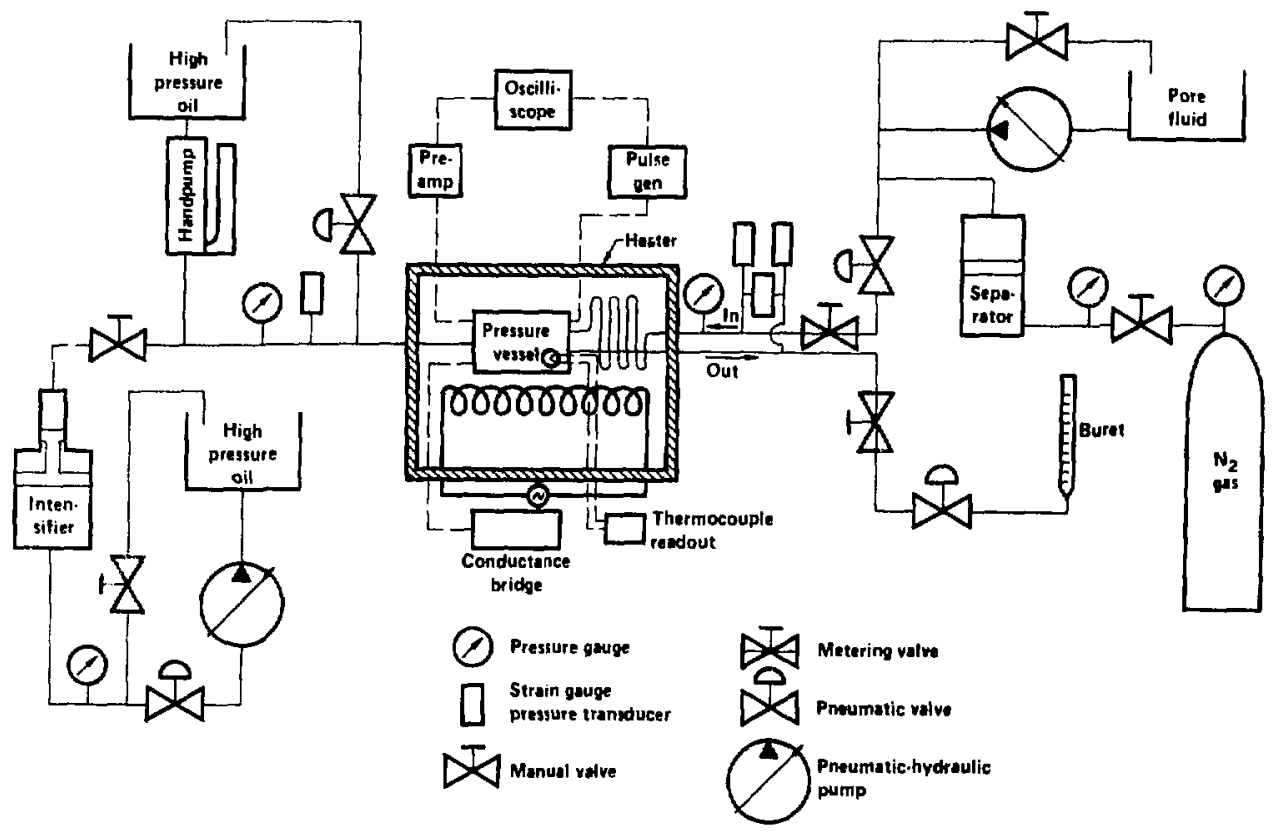

Figure 2. A schematic diagram of the experimental apparatus. The confining pressure system is to the left of the heater; the ultrasonic velocity measurement system is above the heater; the pore fluid pressure system is to the right of the heater. 
inside the pressure vessel about $1 \mathrm{~cm}$ from one end of the rock, measured the sample temperature. The piezoelectric transducer, with a natural frequency of $1 \mathrm{MHz}$, was driven by a 1- $\mu \mathrm{s}$-wide $90-\mathrm{V}$ pulse, generated from a commercial pulse generator. The output of the piezoelectric receiver was preamplified, and the pulse travel time was measured by a time delay oscilloscope.

\section{Data Acquisition}

With multiple variables to be controlled and multiple parameters to be measured on the sample, the experiment could be conducted in a variety of ways. Because the hydrological properties of the rock are of prime importance in maintaining canister integrity as well as waste solation once the canister fails in a repository, we chose to study the water transport in the rock during o.ohydration, rehydration, and full saturation. The experimental procedures were the same for both the intact and fractured samples:

1. The confining pressure was constant throughout the experiment.

2. Electrical resistance measurements were made between each electrode pair (1-2, 3-4, 5-6, $7-8,1-3,3-5,5-7,2-4,4-6$, and $6-8$ ) at least once every hour. When conditions in the sample (for instance, water flow) were changing rapidly, the measurements were repeated as rapidly as once every minute.

3. Ultrasonic P-wave velocity was measured at least once after each significant change in control parameters.

4. Initially, with the sample saturated at room temperature, a permeability measurement was made.

5. The sample was then heated to $140^{\circ} \mathrm{C}$ and the water was allowed to evaporate. The sam- ple was assumed dry when the resistivity reached maximum values and remained constant.

6. The sample was resaturated at $140^{\circ} \mathrm{C}$ by applying $2.5 \mathrm{MPa}$ of water pressure to one end.

7. Permeability was measured when water flow became steady.

8. Again, the sample was dehydrated as in step 5 above.

9. The next rehydration was accomplished at $140^{\circ} \mathrm{C}$ by adding about $0.2 \mathrm{MPa}$ of water pressure to one end. All sample water was in the vapor phase during this period because the water pressure was below the vapor pressure of water at $140^{\circ} \mathrm{C}$.

10. Steam permeability was measured again when the flow became constant. above.

11. The sample was dehydrated as in step 5

12. The temperature was lowered to $98^{\circ} \mathrm{C}$ and $0.2 \mathrm{MPa}$ of water pressure was applied to one end of the rock to resaturate it.

13. Permeability was measured at $98^{\circ} \mathrm{C}$ when the flow became steady.

14. Sample temperature was reduced to $21^{\circ} \mathrm{C}$ and permeability was measured again to compare with the initial permeability measurement.

Because of an unexpected dramatic reduction in water permeability for the first fractured sample after the tests, and the apparent healing of the fracture (see below), a second fractured sample was studied to isolate the main cause of fracture healing. This sample was then taken through step 5, but was nut allowed to dehydrate. The water permeability was then measured as functions of pore pressure difference, temperature (to $140^{\circ} \mathrm{C}$ ), and time. Because of a major decrease in permeability (see Fig. 3), the sample temperature was lowered to $96^{\circ} \mathrm{C}$ and then to $23^{\circ} \mathrm{C}$ while the water permeability was continuously measured. 


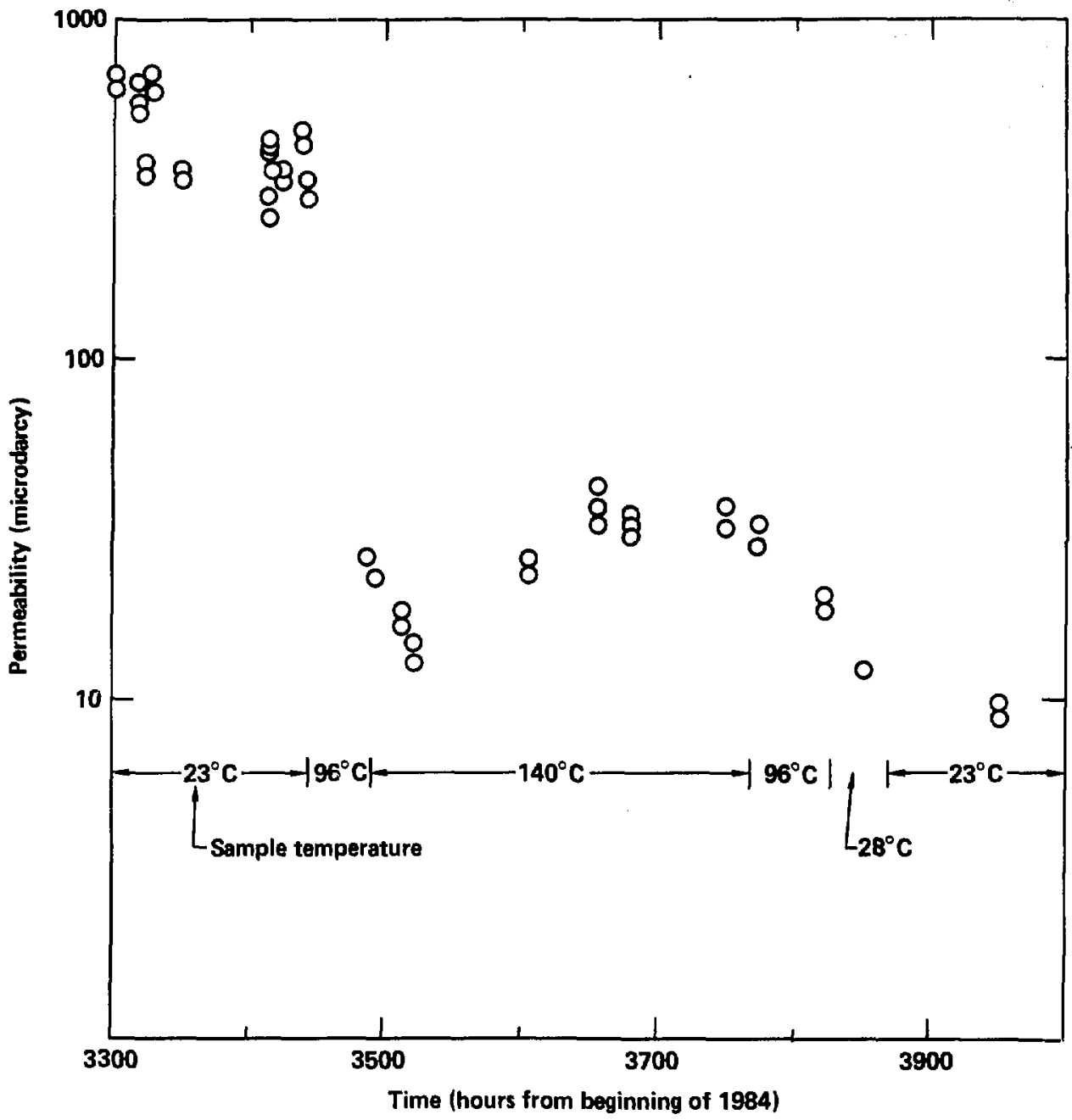

Figure 3. Permeability of the second fractured sample as functions of temperature and time. The time is the hour from the beginning of 1984. The sample was saturated all the time. 


\section{Results and Discussion}

\section{Permeability}

The measured permeability values for the intact and fractured samples are shown in Table 2. Those values designated as "water" were made at sample and pore water temperatures indicated by maintaining a constant pore fluid pressure gradient across the sample and measuring the volume of water that flowed through the sample in a fixed time. Assuming the pore pressure gradient is linear, then the permeability $k$ in darcys is

$\mathrm{k}=\frac{\left(\frac{\Delta \mathrm{V}}{\Delta \mathrm{l}}\right) \times \mu}{\mathrm{A} \times\left(\frac{\Delta \mathrm{P}}{\Delta \mathrm{l}}\right)}$,

where

$\frac{\Delta \mathrm{V}}{\Delta \mathrm{t}}$ is flow rate in $\mathrm{cm}^{3} / \mathrm{s}$.

$\mu$ is fluid viscosity in $\mathrm{cp}$,

$A$ is the cross section area of the sample in $\mathrm{cm}^{2}$, and

$\frac{\Delta \mathrm{P}}{\Delta \mathrm{L}}$ is the pore pressure gradient in bar $/ \mathrm{cm}$.

The values designated as "steam" permeability were obtained from measurements made in the same manner. The actual flow rate of either steam or water at the corresponding pressure and temperature was calculated from the observed flow rate of water from the sample.

Calculation of rock permeability requires measurements of three quantities, each of which has uncertainties that will lead to an error in calculating permeability. In our case, the measurement of pore fluid volume exiting the sample had an uncertainty of about $10 \%$, and the measurement of time had an uncertainty of less than $1 \%$. Although we exerted considerable effort to keep the pore pressure constant during the measurement, we can only estimate the pressure gradient accuracy to be from 2 to $5 \%$. Therefore, the calculated permeability values should have an error of 12 to $15 \%$. The higher permeabilities are the more accurate. The temperature dependence of water or steam viscosity was accounted for in the permeability calculation. ${ }^{8}$

The permeability of the Topopah Spring tuff samples at various experimental conditions is listed in Table 2. The initial room temperature permeability of the fractured sample is more than three orders of magnitude greater than that of the intact sample. The effect of a fracture on permeability has been observed in other rocks, too., 90 Water permeability of the intact sample was independent of temperature and time over the twomonth period of the experiment. The repeated dehydration and rehydration did not affect the permeability of the intact sample, but water permeability of the fractured rocks decreased by more than an order of magnitude after the first dehydration period at $140^{\circ} \mathrm{C}$. After each subsequent drying and resaturation cycle the water permeability in the fractured sample decreased by about one order of magnitude. Steam permeability in the fractured sample was about twice that in the intact sample. The small difference in steam permeability between the fractured and intact samples may be due to fracture healing (see below).

As we mentioned before, the second fractured sample was used to investigate the fracture

Table 2. Fluid permeability of Topopah Spring tuff samples.

\begin{tabular}{lccc}
\hline \multicolumn{1}{c}{ Fluid conditions } & Temperature & lintact & First fractured \\
\hline Water & ${ }^{\circ} \mathrm{C}$ & $\mu \mathrm{D}$ & $\mu \mathrm{D}$ \\
Before drying & 21 & 0.34 & $850 \pm 59$ \\
After the first drying & 140 & 0.31 & $40 \pm 5.2$ \\
After the first drying & 98 & 0.32 & $34 \pm 4.8$ \\
After three drying cycles & 98 & 0.35 & $0.24 \pm \mathbf{0 . 0 7}$ \\
After three drying cycles & 20 & - & $0.40 \pm \mathbf{0 . 0 3}$ \\
Steam & & & \\
After two dryings & 140 & 1.99 & $3.87 \pm \mathbf{0 . 8 2}$ \\
\hline
\end{tabular}


healing. The measured water permeability as a function of temperature and time is shown in Fig. 3. Note that this sample was always kept saturated so that dehydration and rehydration would not affect the water transport. When the sample temperature was raised to $96^{\circ} \mathrm{C}$, the permeability decreased by more than one order of magnitude. Further increases or decreases in sample temperatures did not have a significant effect on the permeability. However, the permeability decrease at $96^{\circ} \mathrm{C}$ was not due primarily to temperature but rather to healing of the fracture by mineral deposition. This phenomenon will be cilscussed in more detail later.

\section{Dehydration Process}

As we discussed hefore, one of our experimental measurements is the distribution of electrical resistivity in the sample as a function of time. Figure 4 shows the resistivity of the intact Topopah Spring tuff sample measured from electrode pair 7-8, the upstream electrode pair (as shown in Fig. 1, the electrodes closest to the end where water is introduced). The major variations of resistivity shown in this figure correspond to drying, resaturation, and temperature changes during various stages of the experiment. Initially, the sample is saturated with J-13 water and the resistivity is about $500 \mathrm{ohm}-\mathrm{m}$ (hour 4035). The first drying period is between hour 4100 and hour 4600 . The rapid decrease of resistivity at hour 4600 corresponds to the introduction of J-13 water at $2.5 \mathrm{MPa}$ of pressure. The resistivity increase from $400 \mathrm{ohm}-\mathrm{m}$ to about $600 \mathrm{ohm}-\mathrm{m}$ at about hour 4660 corresponds to a decrease of sample temperature from 140 to $95^{\circ} \mathrm{C}$. The second drying period is between hours 4710 and 5337. The rapid decrease in resistivity following the second drying period is due to the addition of steam (at $140^{\circ} \mathrm{C}$ and $0.25 \mathrm{MPa}$ of pressure) to the sample. Between hours 5352 and 5636, steam flows continuously through the sample. The third drying period at $140^{\circ} \mathrm{C}$ starts at hour 5636 , then the temperature is reduced to $98^{\circ} \mathrm{C}$ at hour 5800 . Then, at about hour 5900 , water at $2.5 \mathrm{MPa}$ of pressure is added to the sample. From hour 5900 to hour 6036, water at $98^{\circ} \mathrm{C}$ is flowing through the sample.

Figure 5 shows a similar resistivity plot of the fractured sample. Figures 4 and 5 show that the drying process in some parts of the rocks can be roughly differentiated into two parts-a rapid increase in resistivity (the first drying stage), probably due to the quick escape of water from the sample, and a much slower increase in resistivity

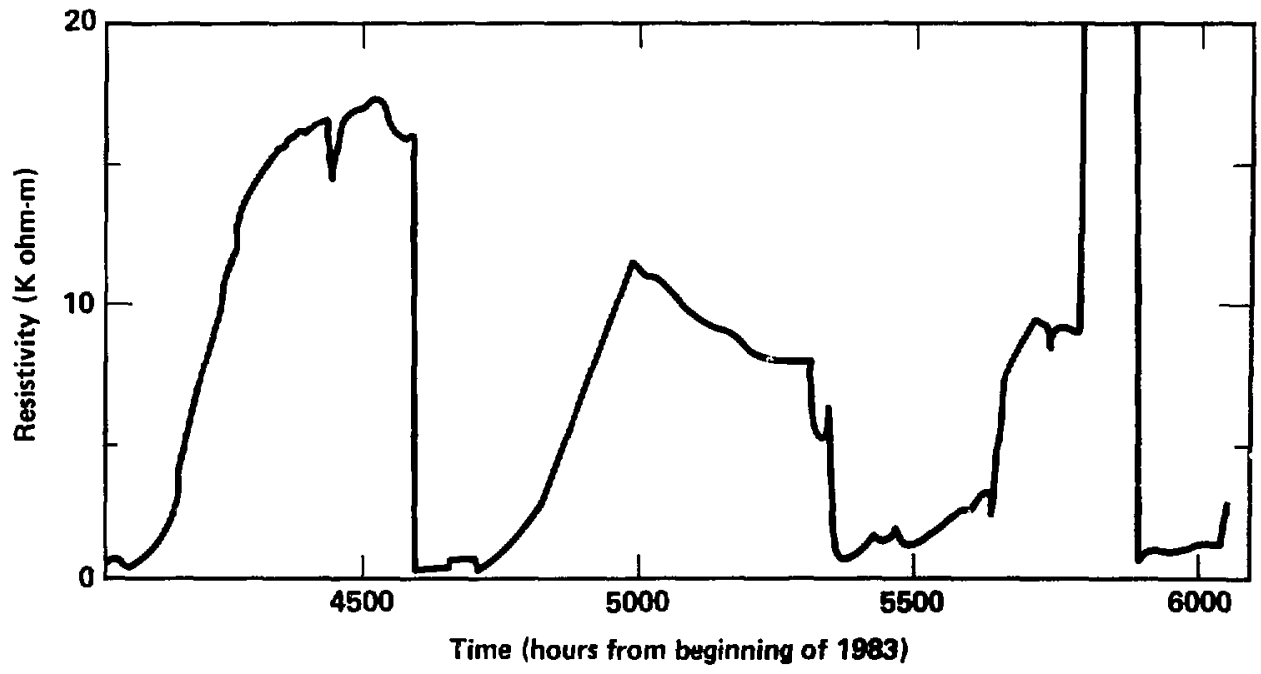

Figure 4. Electrical resistivity from electrode pair 7-8 (upstream) of the intact Topopah Spring tuff sample as a function of time. The time is in hours from January 1, 1983. 


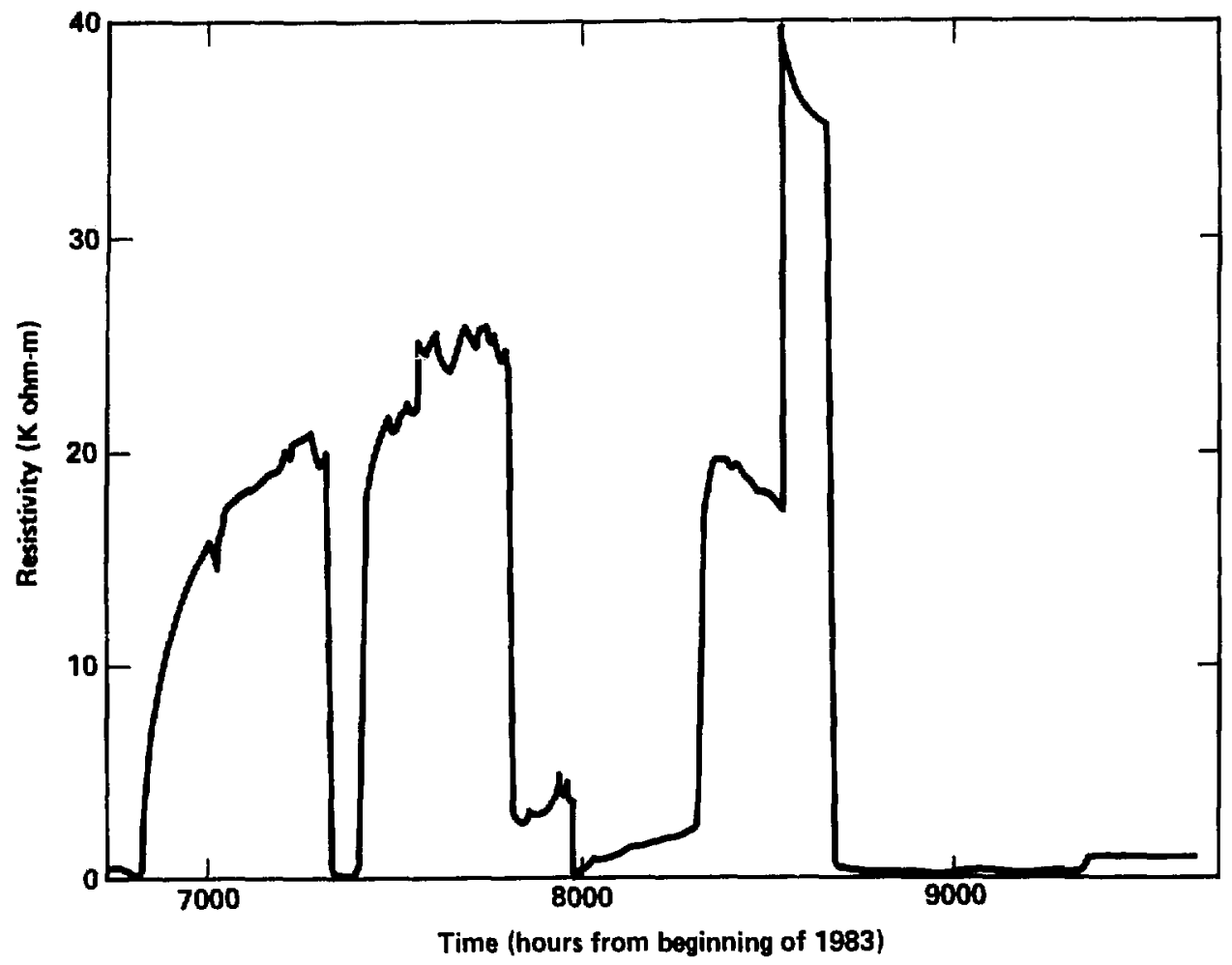

Figure 5. Electrical resistivity from electrode pair 7-8 (upstream) of the first fractured Topopah spring tuff as a function of time. The time is in hours from January $1,1983$.

(the second drying stage), probably due to the slow release of moisture held in microfractures or microcavities.

The only significant difference in the drying periods for the intact and fractured samples is during the first drying stage, when water escaped relatively rapidly. The first drying stage of the intact sample is at least eight times slower than that of the fractured sample. This implies that the fracture provided a conduit for escape of the steam. Between hours 4990 and 5300 , the intact sample shows a decrease of resistivity with time during dehydration at $140^{\circ} \mathrm{C}$. This may be due to a slow contact area increase between mineral grains as stresses along grain boundaries relax at this temperature. However, scanning electron microscopy of this sample does not -eveal significant changes in texture before and after the experiment. Al- though no significant permanent deformation occurred, slight grain movement may have occurred to cause the measured resistivity drift. In the fractured sample (Fig. 5), the second drying stage of the second drying period is shorter than that in the first drying period. This may indicate that during the first water flowing period (after the first drying period) the sample was not fully resaturated so that the amount of moisture stored in the matrix of the sample was less than when the sample was saturated before the first drying period.

The resistivity vs time behavior of the intact and fractured sample during the third drying period (after the steam flow) is about the same. During this dehydration, both samples show resistivity maxima followed by a decrease of resistivity with time. If this resistivity decrease is due to 
gradual grain boundary relaxation and an increased contact area between grains (as discussed above), then it seems to take longer for the intact sample to completely dry than the fractured sample.

To illustrate the drying process, we plot the relative variation of electrical resistivity in the plane containing the electrodes as a function of time. For the fractured sam!ia, this plane is also very close to the fracture plane (see Fig. 1). These plots of the first drying perind for both intact and fractured samples are shown in Fig. 6. The plane is divided into 10 areas, each containing the predominant current of an electrode pair used for a resistivity measurement (see "Experlmental Procedures"),

From Fig, 6, we see that must of the percentage change of the intact sample resistivity takes place rapidly between the second and the tentin day. It also shows that the sample drled out fairly uniformly except at a few isolated locations: near electrodes 3-4, it dried slower, and near electrodes 6-8, it dried faster. On the other hand, drying of the fractured sample is quite nonuniform. It dried out from the upstream end first. itso, the upper right corner (electrodes 5-7) dried faster than the lower left corner (electrodes 2-4). The nonuniform drying may be due to the ough fracture surface. Although dehydration time was roughly equivalent for the fractured and intact samples, the fracture apparently influenced the drying process. However, it is not clear why the moisture distribution, but not the evaporation rate, would be affected by the presence of the fra:ture.

\section{Rehydration Process}

As shown in Figs. 4 and 5, three resaturation tests were done on the infact and first fractured samples: (1) resaturation with an upstream water pressure of $2.5 \mathrm{MPa}$ and sample temperatures of $140^{\circ} \mathrm{C}$; (2) resaturation with an upstream water pressure of $0.25 \mathrm{MPa}$ at $140^{\circ} \mathrm{C} i$ and (3) resaturation with an upstream water pressure of about $0.5 \mathrm{MPa}$ at $98^{\circ} \mathrm{C}$. In the first case, the saturation fluid was liquid water, which was probably precedrd by a steam front because the pore pressure must fall to ambient at the leading edge; in the second case, the saturation fluid was steam; and in the third case, the saturation fluid was liquid water. To illustrate the resaturation process, the spatial distribution of the resitivities of the fractured samp!e for steam saturation and the intact and fractured samples for water saturation are shown in Fig. 7.
Figure 7 shows that just ahead of the saturation front. whether steam or water, the resistivity increases before the expected decrease. This is probaoly due to local stress variations in the dry rock just ahead of part of the rock witii a nonzero pore pressure. In the intact sample, the satursiting fluid propagated along the sample with a fairly uniform frnnt perpendicular to the flow direction. On the other hand, in the fractured sample, the flow of water in the fracture was quite notiuniform. The water seemed to wet one side (electrodes 2, 4, 6, and 8) first. That side of the sample happens to be the lower side in the figure. Actually, the fracture orientation in the vessel with respect to gravlty during the experiments is unknown. However, it is likely that the fracture roughness contributed to the nonuniform flow of water.

When stean. was applied to the fractured sample, the flow pattern was more uniform thar. that of water flow. It should be noted that the changes in resistivity due to the steam flow registered by the downstream electrodes were mucn smaller than resistivity changes from the upstream electrodes. This is probably due to the pore p:essure gradient between the upstream and downstream end. At the upstream end, the pore pressure was $0.3 \mathrm{MPa}$ whereas the pore pressure at the downstream end was $0.1 \mathrm{MPa}$. Therefore, at the upstream end, the steam was wetter than at the downstream end.

For both intact and fractured samples, the resistivity during the steam saturation period increased with time when the steam flow became steady. One possible interpretation of this phenomenon is that the porosity in the samples gradually decreased at the temperature and pressure conditions. This is the same conclusion we reached from the gradual decrease in sample resistivity when dry. Therefore, both data sets imply a slow relaxation of the sample, perhaps resulting in an increase in density, after a few weeks at $140^{\circ} \mathrm{C}$ and $5.0 \mathrm{MPa}$ of pressure.

To estimate the speed of the water front propagating along the sample (wetting front speed), we use the resistivity variation measured from the electrode pairs directly across the sample $(1-2,3-4,5-6$, and $7-8)$. A response time for each resistivity-time curve from these electrode pairs is determined. This response time is arbitrarily definec as the time when the resistivity has decreased by $10 \%$ of its total change from the dry to the saturated state. For example, in Fig. 8, the response time is plotted as a function of the electrode location. The inverse slope of a straight line 
(a)

Intact
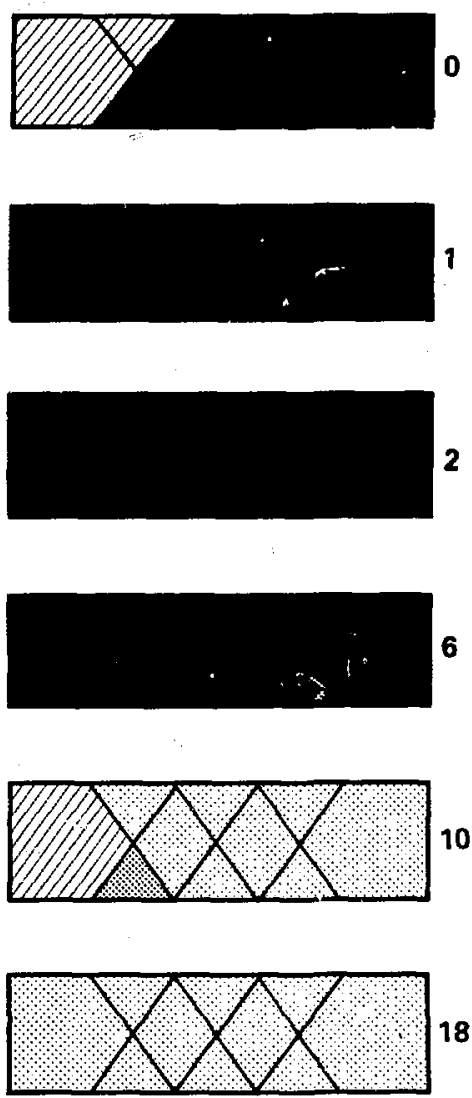

Time,

days

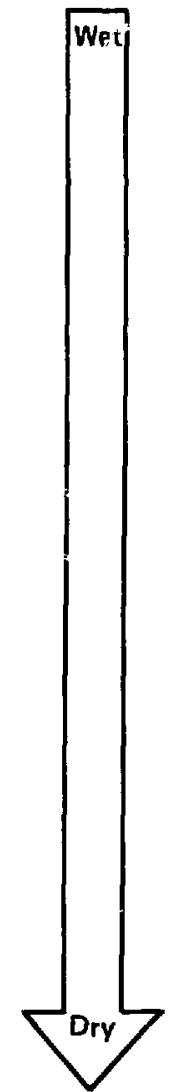

(b)

Fractured

$\mathbf{0}$

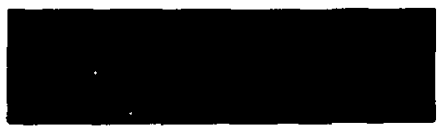

2

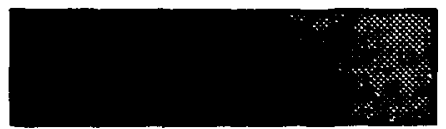

4

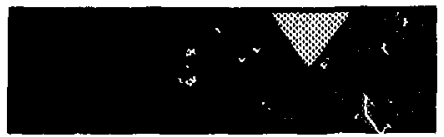

8

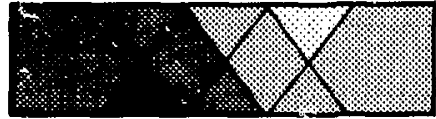

12

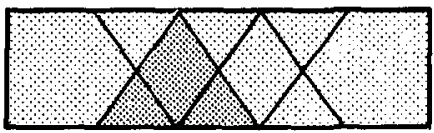

19

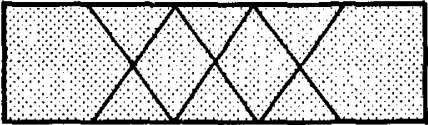

Resistivity change from saturation

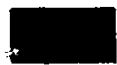

0-19\% (saturated sample)

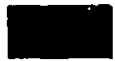

$20-39 \%$

$40-59 \%$

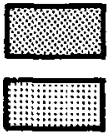

$60-79 \%$

80-100\% (dry sample)

No data

Figure 6. Spatial distribution of electrical resistivity (in $\mathbf{k} \Omega-m$ ) in the plane containing the electrodes of the (a) intact and (b) first-fractured Topopah Spring tuff samples during the first drying period. The time scale is in days since the beginning of drying. 
(a)
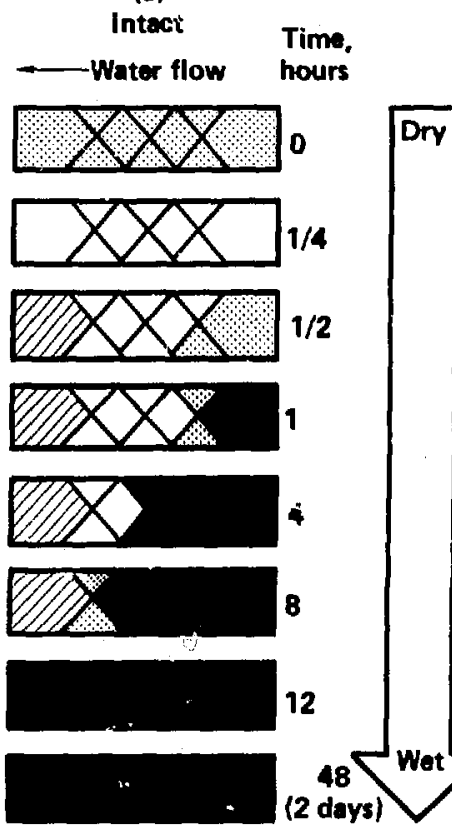

(2 days) (b)

Time,

Fractured

min - Woter flow

$\mathbf{0}$

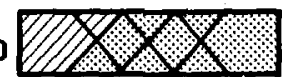

1

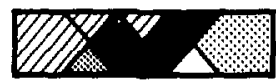

2

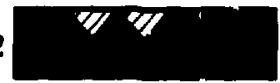

3

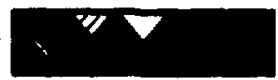

6

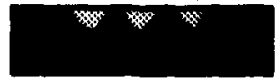

9

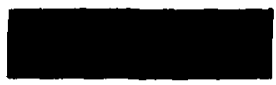

12

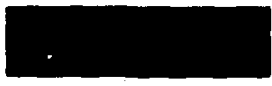

4320

(3 days) (c)

Fractured

Time Steam flow

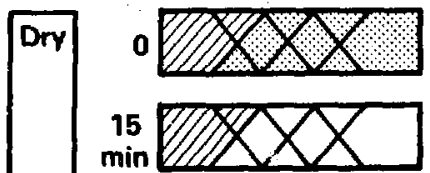

27

min

48

min

62

min

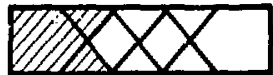

6

hrs

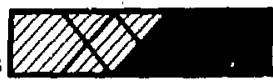

12

hrs

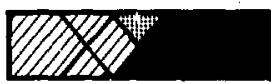

18

hrs

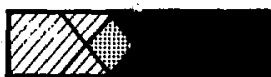

24

hrs

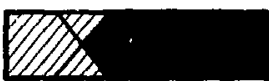

36

hrs

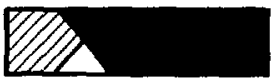

$$
2
$$

days

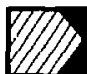

3

days

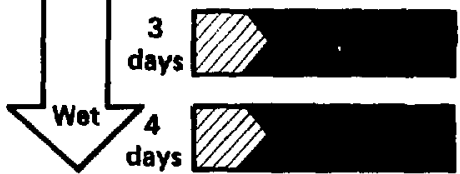

3 80-100\% (dry sample)

$>100 \%$

QZ7 Resistance off scale

Figure 7. Spatial distribution of electrical resistivity $(\mathrm{k} \boldsymbol{\Omega}-\mathrm{m})$ in the plane containing the electrodes of the (a) intact and (b) first-fractured Topopah Spring tuff samples during the water rehydration period at $140^{\circ} \mathrm{C}$. (c) Is the same plot of the first fractured sample during the steam rehydration period at $140^{\circ} \mathrm{C}$. The time scale starts from the beginning of each rehydration period. 


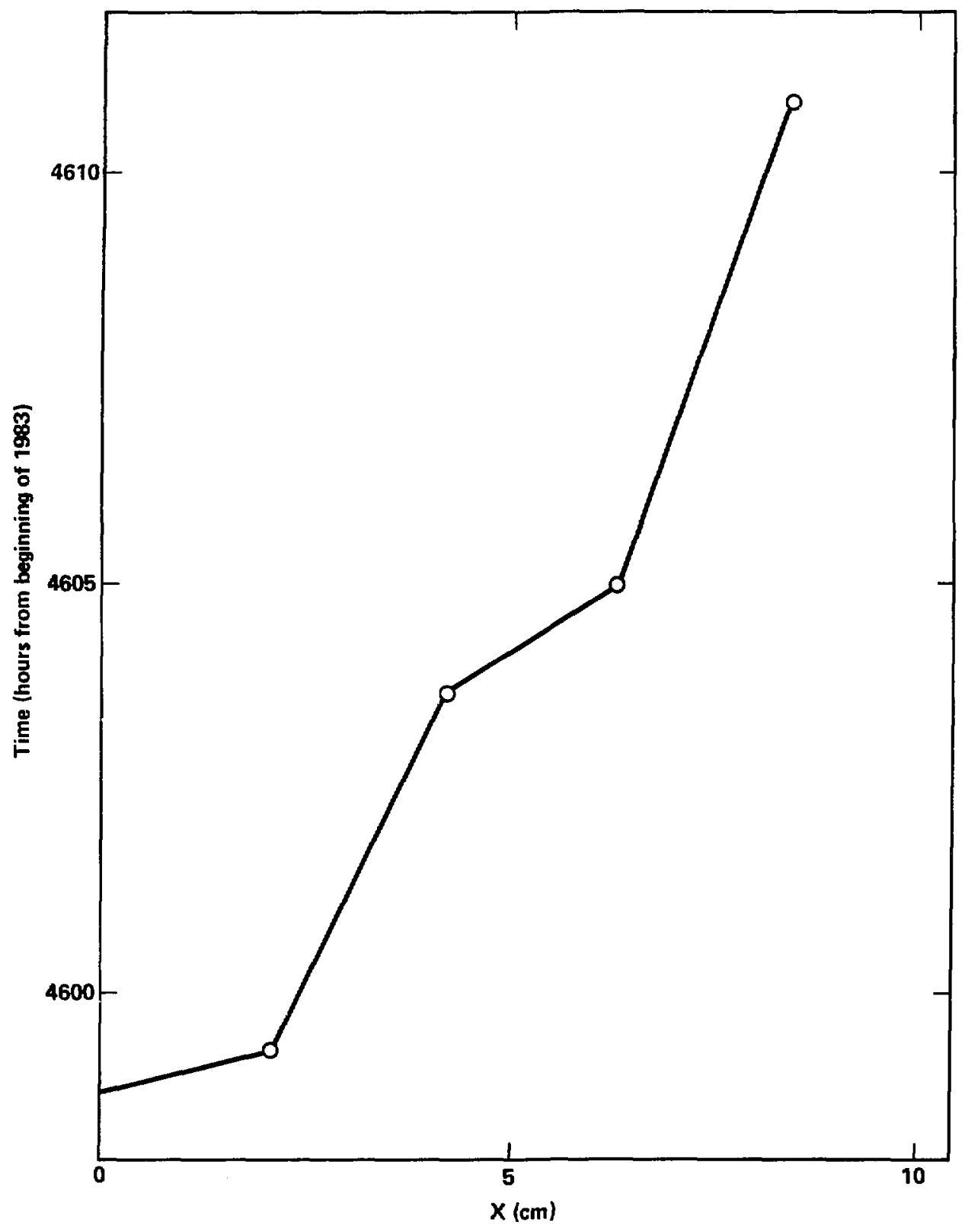

Figure 8. Response time (from January 1, 1983) of the four electrode pairs transverse to the intact sample axis during the firt water rehydration period at $140^{\circ} \mathrm{C}$. $X$, in $\mathrm{cm}$, is the location of the electrode pairs. The inverse slope is the wetting front speed. 
best fitting these data gives an estimation of the wetting front speed.

Table 3 lists the wetting front speed of the intact and fractured samples in the three resaturation cycles. Also shown in Table 3 is the effective steady-state pore fluid speed from the measured permeability and pressure difference across the sample. The effective steady state speed of the fractured sample is calculated for comparison only. The actual steady state speed in the fracture may be higher than that shown in Table 3. The wetting front speed of water is significantly greater than the effective steady state speed. In the case of saturation with steam, the two are nearly the same.

The data in Fig. 8 show a nonlinear relation between time and wetting front position, indicating either nonuniform flow speed or nonuniform distribution of pore pressure along the flow direction. Gale ${ }^{11}$ measured pore fluid pressure at three equally spaced locations along a natural fracture in a $10-\mathrm{cm}$-diameter, $20-\mathrm{cm}$-long granite sample. The sample was at $35 \mathrm{MPa}$ of confining pressure and $3.0 \mathrm{MPa}$ of pore pressure at one end. He observed a nonlinear distribution of pore fluid pressure along the fracture.

\section{Ultrasonic Velocity}

The P-wave ultrasonic velocity along the sample axis was also measured at various times during the experiment on both intact and fractured samples. The results for the intact and fractured samples are shown in Figs. $Y(a)$ and (b), respectively. Both figures show that $P$-wave velocity increases by about $20 \%$ from dry to saturated conditions. However, the measurement was not sensitive enough to yield detaileu information about the dehydration and re'iydration *ocesses. This is probably because the propagation path is parallel to the direction of water flow. Both the intact and fractured samples show that P-wave velocity does not change significantly between dry and steam-saturated states.

The velocity in the fractured sample resaturated with water at 98 and $20^{\circ} \mathrm{C}$ after three drying cycles is abnormally low (Fig. 9). This is quite a contrast to the intact sample. The most likely explanation is that the matrix of the fractured samiple was not fully resaturated. In other words, when water or steam is applied to the sample, it flows most easily through the fracture and is not forced into the matrix.

\section{Fracture Healing}

As discussed earlier, the permeability of the first fractured sample decreased by more than three orders of magnitude by the end of the experiment. When the sample was removed from the pressure vessel, we found the fracture had healed so that the sample pieces were bonded together. Scanning electron microscopy (SEM) shows layers of silica deposition on the fracture after the drying and resaturation cycles (Fig. 10). Brazilian testing showed that the tensile strength of the healed fracture is about half that of the intact sample (5 $\mathrm{MPa}$ for the healed fracture, $9 \mathrm{MPa}$. for the intact sample).

As mentioned earlier, the fractured sample initially contained a reopened, naturally healed fracture. This fracture was coated with white silica on the fracture surface before the testing. Therefore, the healing probably occurred when this secondary mineral migrated by water on the fracture surface at the pressure and temperature conditions in the tests. The factors that may have contributed to the fracture healing were pressure,

Table 3. Wetling front speed $\left(V_{W}\right)$ and effective steady state flow speed $\left(V_{s}\right)$, in $\mathrm{cm} / \mathrm{s}$, for the intact and fractured Topopah Spring tuff.

\begin{tabular}{|c|c|c|c|c|c|c|c|}
\hline & \multicolumn{4}{|c|}{ Intact } & \multicolumn{3}{|c|}{ Fractured } \\
\hline & $\mathbf{T}\left({ }^{\circ} \mathrm{C}\right)$ & $\Delta \mathbf{P}(\mathbf{M P a})$ & $\mathbf{v}_{\mathbf{w}}$ & V. & $\Delta P(M P a)$ & $\mathbf{v}_{\mathbf{w}}$ & $\mathbf{V}_{3}$ \\
\hline Water & 140 & 2.5 & $1.5 \times 10^{-4}$ & $3.7 \times 10^{-6}$ & 1.5 & $1 \times 10^{-2^{4}}$ & $3.2 \times 10^{-1^{6}}$ \\
\hline Steam & 140 & 0.3 & $8.1 \times 10^{-3}$ & $4.1 \times 10^{-5}$ & 0.2 & $3.2 \times 10^{-4}$ & $6 \times 10^{-3}$ \\
\hline Water & 98 & 2.5 & $1.2 \times 10^{-4^{6}}$ & $3 \times 10^{-6}$ & 0.2 & $1.8 \times 10^{-5}$ & $1.8 \times 10^{-7}$ \\
\hline
\end{tabular}



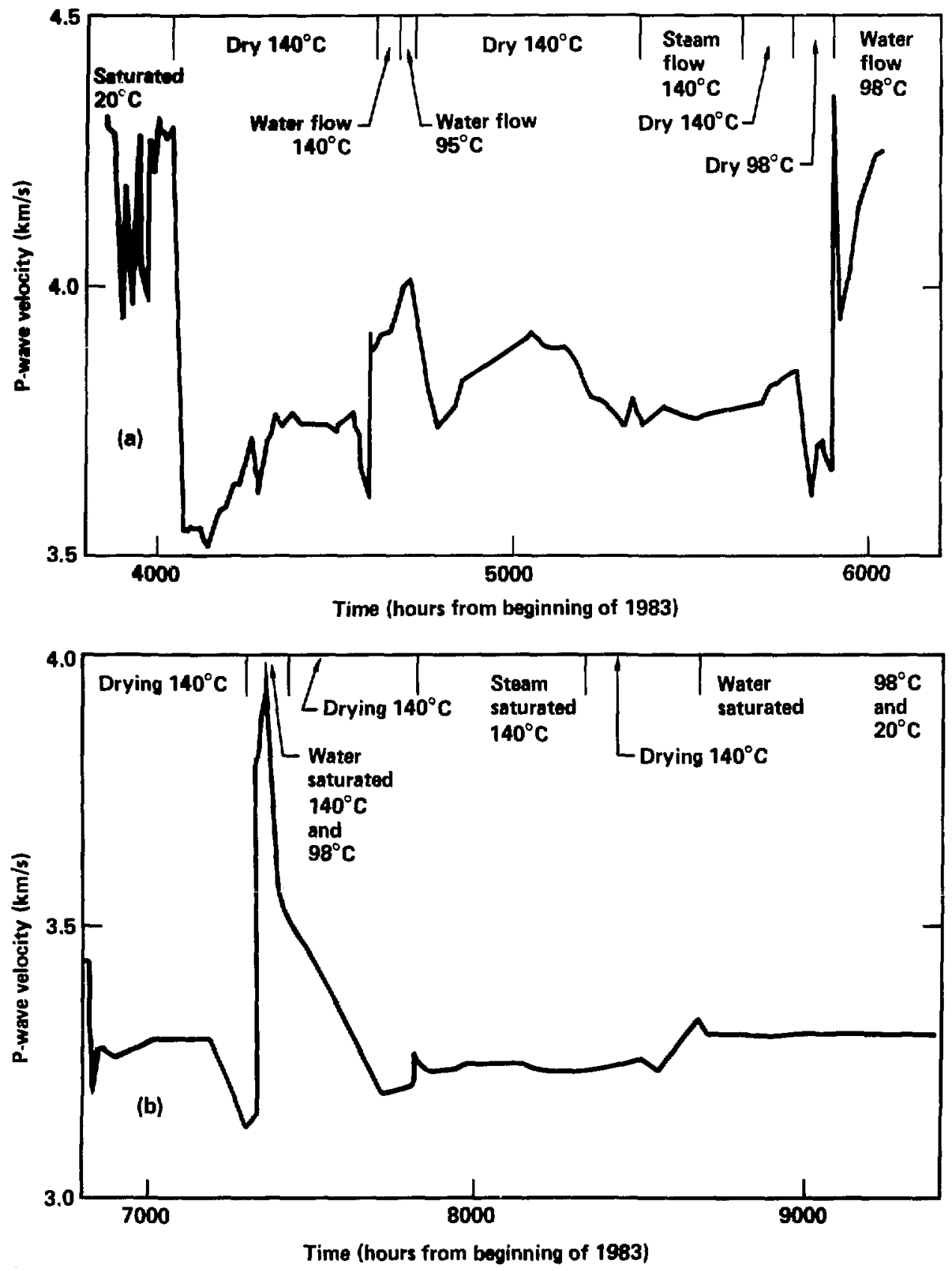

Figure 9. Ultrasonic P-wave velocity measured along the sample axis of the (a) intact and (b) fractured Topopah Spring tuff sample as a function of time. The time scale is from January 1, 1983. 


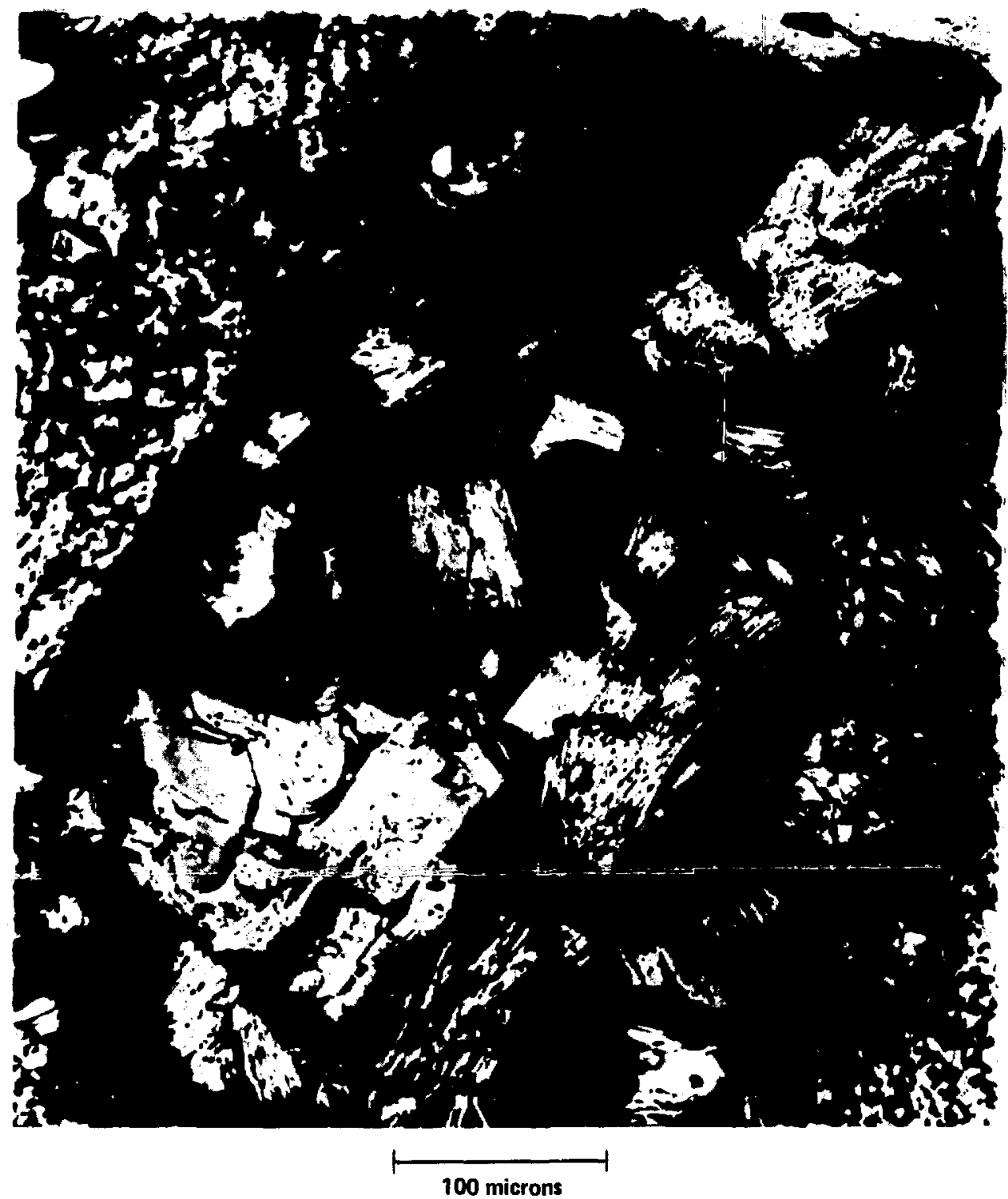

Figure 10. SEM photograph of the fracture surface (edge on view) of the first fractured Topopah Spring tuff sample after the experiment. A layered silica deposit is shown. The sample had gone through three dehydration and rehydration cycles in four months. 
temperature, drying and resaturation cycles, and time. To isolate the main factor contributing to the fracture healing, we tested a second fracturea sample containing a natural fracture with surface conditions similar to the first. A carefully planned test procedure was used to distinguish among the above possible factors that may have affected the healing processes.

Figure 3 shows the permeability history of the second fractured sample. Permeability decreased more than one order of magnitude when the temperature increased from 23 to $96^{\circ} \mathrm{C}$. This is similar to the permeability decrease in the first fractured sample after each drying and resaturation cycle. After the major decrease in permeability at $96^{\circ} \mathrm{C}$, the permeability of the second fractured samples did not clearly correlate with either time or temperature.
Note that the permeability decrease at $96^{\circ} \mathrm{C}$ did not recover when the sample temperature was iowered to $23^{\circ} \mathrm{C}$. Also, the sample was not dehydrated in this test; therefore, the permeability decrease cannot be attributed to a deposit formed by evaporation filling the fracture. Scanning electron microscopy showed deposition of silica very similar to that on the first fractured sample (Fig. 11). However, the fracture was not healed to the same extent as was the first fractured sample. This test indicates that fracture healing by water transport of minerais (mainly silica) in the fracture occurs as temperature increases to about $100^{\circ} \mathrm{C}$. However, we have not yet investigated whether further fracture healing is induced by elevated temperatures alone or whether other factors are important. This iracture healing phenomenon should be investigated in more detail.

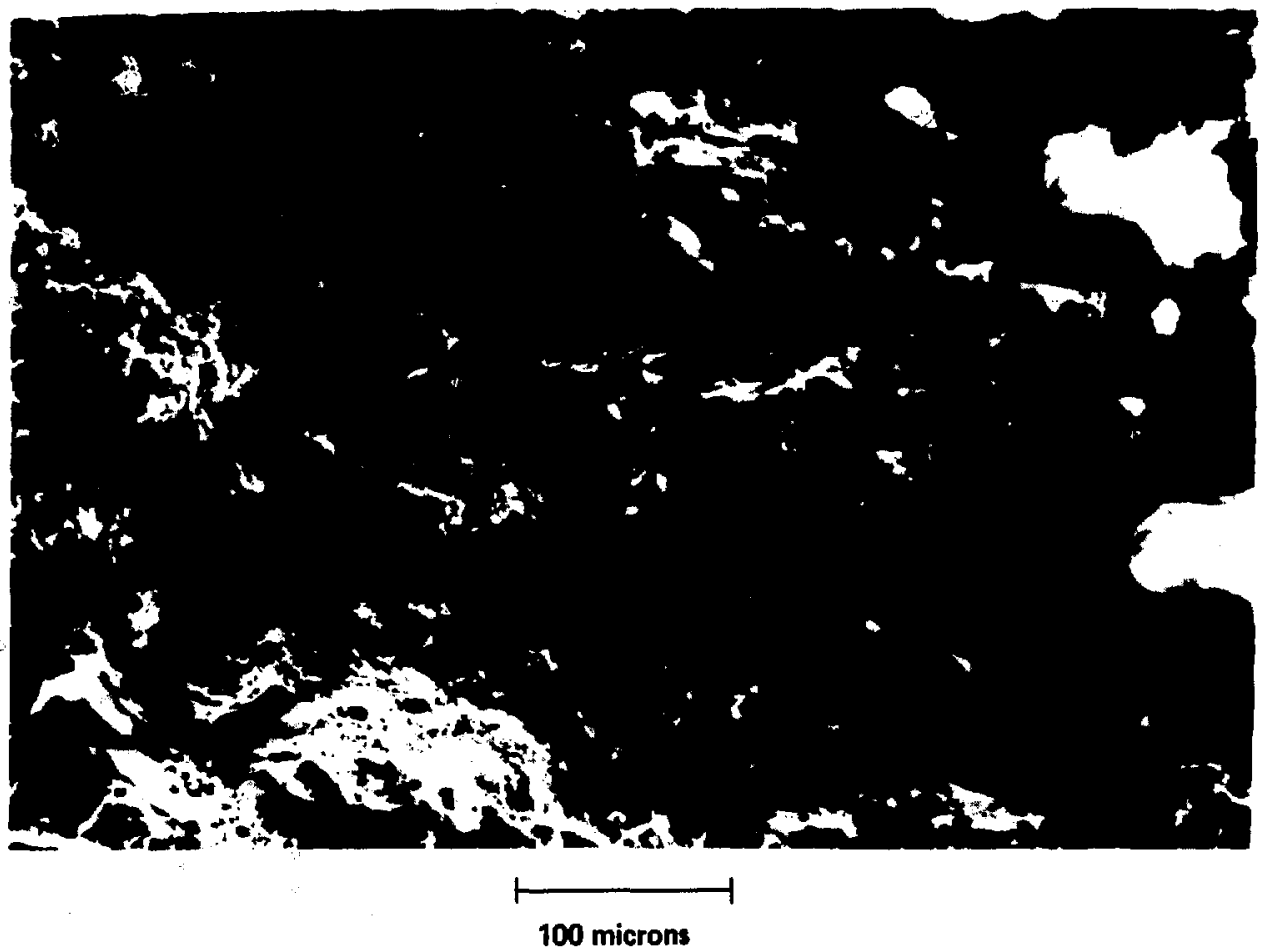

Figure 11. SEM photo of the iracture surface of the second fractured Topopah Spring tuff sample. The sample had gone through thermal cycles to $140^{\circ} \mathrm{C}$ during 27 days. The sample was always saturated. 


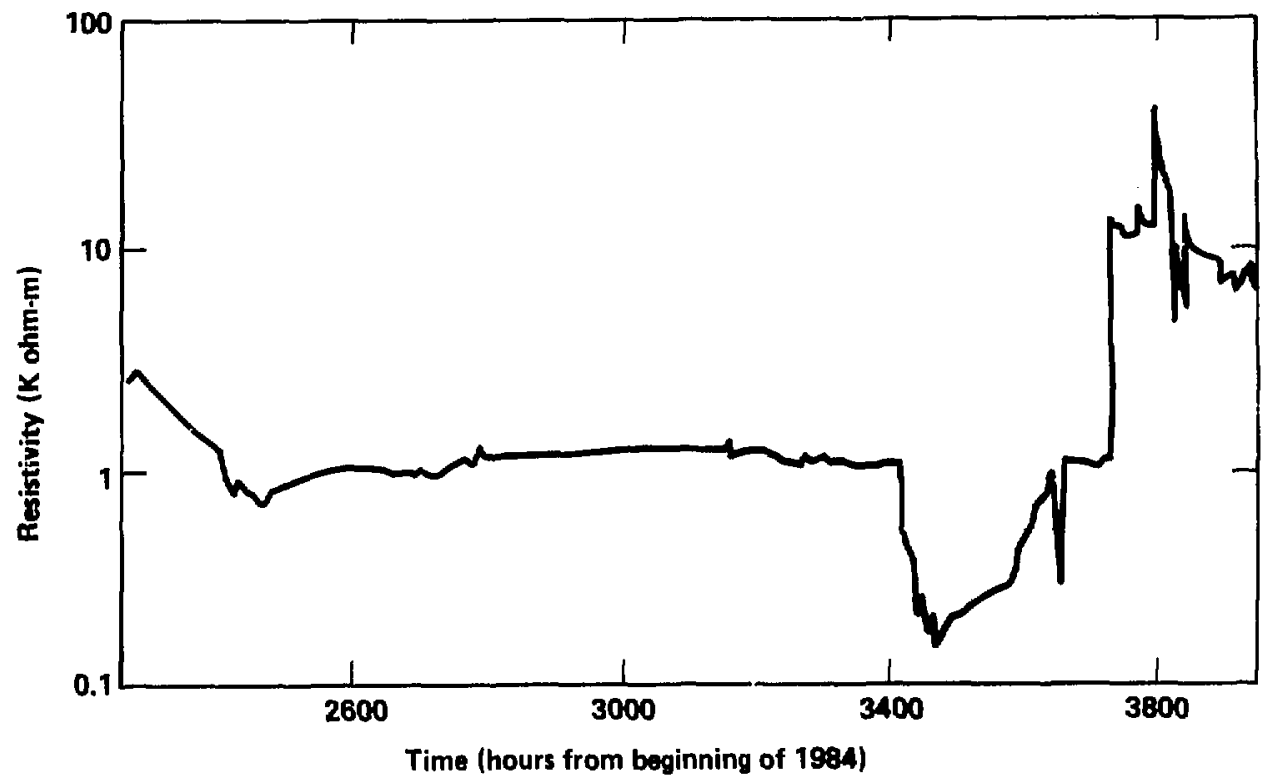

Figure 12. Electrical resistivity from the electrode pair 7-8 of the second fractured Topopah Spring tuff sample as a function of time. The time is from January $1,1984$.

Figure 12 shows part of the electrical resistivity history of the second fractured sample from electrode pair 7-8 where current is predominately parallel to the fracture. When the temperature was held at $140^{\circ} \mathrm{C}$, the resistivity increased by almost an order of magnitude to the same value as at $23^{\circ} \mathrm{C}$. And, when temperature was decreased to $96^{\circ} \mathrm{C}$, the resistivity returned to a value almost two orders of magnitude greater than when the sample temperature was first at $96^{\circ} \mathrm{C}$. However, a further decrease in temperature did not cause a significant resistivity change. These changes in resistivity can be associated with the fracture healing that caused the permeability decrease. It should be noted that the inhomogeneity of the sample plays an important role in the measured resistivity. The resistivity measured by the electrode pair 3-4-another pair mounted so that current is mostly parallel to the fracture-increased oniy about six times, instead of almost two orders of magnitude, as shown in Fig. 12. As depicted in Fig. 5, the electrical resistivity measurements in the first fractured sample did not demonstrate significant fracture healing.

\section{Conclusions}

Our experiment shows that electrical resistivity measurements can be used to monitor fluid flow in either intact or fractured rock. With additional information relating electrical resistivity and the degree of saturation, our experimental resuits (dehydration history and rehydration his- tory) could be used in numerical models for understanding and monitoring fluid flow in an underground radioactive waste repository.

The ultrasonic velocity, when measured parallel to the fracture, also showed the difference between dry and saturated conditions. However, 
the velocity measurement did not give as detailed information on the dehydration and rehydration processes as did the resistivity measurements.

For both intact and fractured samples, at least in some areas, the drying process was accomplished in two stages-a fast release of water followed by a much slower release of moisture held in microfractures or microcavities. The drying in the intact sample took place fairly uniformly. In the fractured sample, one corner dried out first. The nonuniform drying process in the fractured sample may be due to the rough fracture surface.

The rehydration in the intact sample took place fairly uniformly. The wetting fluid propagated along the sample with a fairly uniform front perpendicular to the flow direction. For the fractured sample, however, one side of the fracture was wetted first. Again, the roughness of the fracture surface may have caused the nonuniformity of the saturation process. When water at a few megapascals was introduced into the sample, the wetting front in the fractured sample moved at a speed about 100 times faster than in the intact sample.

The permeability of the intact sample was independent of temperature, dehydration and rehydration cycles, and time. However, for the fractured sample, the permeability decreased by more than one order of magnitude after each dehydration and reisydration cycle. In the entire testing period of about four months, the permeability of the fractured sample decreased by more than three orders of magnitude ( 850 to $0.3 \mu \mathrm{d}$ ). Fracture healing seems to be the main contributor to the decrease of permeability. Testing of a second fractured sample indicated that the fractura began to heal when the sample temperature was increased to $96^{\circ} \mathrm{C}$ without dehydration, probably as a result of redeposition of minerals such as silica. The mechanism of further fracture healing should be investigated more.

\section{Acknowledgments}

The authors are grateful to $\mathrm{H}$. Heard, J. Lytle, and V. Oversby of LLNL for helpful discussions. J. Carbino provided valuable technical support, while J. Beatty, M. Christensen, and E. Arnold provided computer support for the experiment. The scanning electron microscope investigations were performed by K. Knauss of LLNL. A. Duba, H. Heard, and V. Oversby made comments that greatly improved the manuscript.

This work was supported by the Waste Package Task of the NNWSI Project. 


\section{References}

1. H. S. Swolfs, "Chemical Effects of Pore Fluid on Rock Properties," Ant. Assoc. Petrol. Geol. Mem. 18, Pp. 224-234 (1974).

2. P. A. Witherspon and J. E. Gale, "Mechanical and Hydraulic Properties of Rocks Related to Induced Seismicity," Entg. Geol. II, pp. 23-55 (1977).

3. A. Nur and G. Simmons, "The Effect of Saturations on Velocity in Low Porosity Rocks," Earth Planet. Sci. Lett. 1, p. 183 (1969).

4. J. B. Walsh, "New Analysis of Attenuation in Partially Melted Rock," J. Geophys. Res. 74, Pp. 4333-4337 (1969).

5. R. J. O'Connell and B. Budiansky, "Seismic Velocities in Dry and Saturated Cracked Solids," J. Geophys. Res. 79, pp. 5412-5426 (1974).

6. K.G. Knauss, Petrologic and Geochemical Characterization of the Topopah Spring Member of the Paintbrush Tuff: Outcrop Samples Used in Waste Package Experiments, Lawrence Livermore National Laboratory, Livermore, CA, UCRL-53558 (1984).

7. D. L. Bish, F. A. Caporuscio, J. F. Copp, B. M. Crowe, J. D. Purson, J. R. Smyth, and R. G. Warren, Preliminary Stratigraphic and Peirologic Characterization of Core Samples from USW-G1, Yucca Mountain, Nevada, Los Alamos National Laboratory, Los Alamos, NM, LA-8840-MS (1981).

8. D. Eisenberg and $W^{\prime}$ Kauzmann, The Structure and Properties of Water (Oxford Press, New York, NY, 1969).

9. W. Lin, Measurint thr: Permeability of Eleana Argillite from Area 17, Nevada Test Site, Using the Transient Method, Lawrence Livermore National Laboratory, Livermore, CA, UCRL-52604 (1978).

10. W. Daily and W. Lin, Laboratory Determined Transport Properties of Berea Sandstone, Lawrence Livermore National Laboratory, Livermore, CA, UCRL-89308 (1983).

11. J. Gale, personal communication, Dept. of Earth Sciences, University of New Foundland, New Foundland, Canada (1984). 